\title{
Virtual Reality Technology for Rehabilitation of Cerebral Palsy: A Literature Review
}

\author{
Fabiana Rita Camara Machado ${ }^{1}$ \\ Hospital de Clínicas de Porto Alegre, Porto Alegre, Rio Grande do Sul, Brasil \\ Universidade Federal de Ciências da Saúde de Porto Alegre, Programa de Pós-Graduação \\ em Ciências da Reabilitação, Porto Alegre, Rio Grande do Sul, Brasil \\ Priscilla Pereira Antunes \\ Jandara de Moura Souza \\ Daniela Centenaro Levandowski \\ Alcyr Alves de Oliveira Jr. \\ Universidade Federal de Ciências da Saúde de Porto Alegre, Programa de Pós-Graduação \\ em Ciências da Reabilitação, Porto Alegre, Rio Grande do Sul, Brasil
}

\begin{abstract}
Cerebral palsy (CP) is a non-progressive encephalopathy that causes changes in muscle tone, posture and movement. The importance of early rehabilitation intervention is widely recognized, and new treatment tools such as computational technologies have been added for rehabilitation. The use of computational virtual reality games raises the possibility to control the training intensity as well as to observe the progress and direct monitoring control over patients' activities. Additionally, some studies have shown the effectiveness of these systems in improving the management of tasks for patients with various levels of encephalopathy. Based on the assumptions above, the objective of this review was to discuss the literature on the use of such technologies in the rehabilitation of CP patients. The potential use of VR in rehabilitation of $\mathrm{CP}$ patients is clear. There is, however, a reduced number of randomized trials to sustain whether these methods may effectively act as a complement for physical and/or neuro-cognitive rehabilitation or work as a replacement for the traditional rehabilitation methods.
\end{abstract}

Keywords: Rehabilitation, virtual reality, cerebral palsy.

\section{Tecnologia Computacional de Realidade Virtual Aplicada à Reabilitação em Paralisia Cerebral: Uma Revisão de Literatura}

\section{Resumo}

A paralisia cerebral (PC) é uma encefalopatia não progressiva que provoca alterações de tônus, postura e movimento. A importância da intervenção precoce na PC é amplamente reconhecida. Novas ferramentas para tratamento, como as tecnologias computacionais, tem contribuído para a reabilitação desses pacientes. Jogos interativos e de realidade virtual (RV) permitem manipular a intensidade do treinamento, acompanhar o progresso e as atividades do paciente. Alguns estudos demonstram a eficácia do uso

Mailing address: Department of Psychology, Federal University of Health Sciences of Porto Alegre, Rua Sarmento Leite, 245, Centro, Porto Alegre, RS, Brazil 90050-170. E-mail: fabianarita@gmail.com, prisantunes@hotmail.com, jandara.souza@gmail.com,danielal@ufcspa.edu.br and alcyr@ufcspa.edu.br 
desses sistemas para a melhoria da administração de tarefas para pessoas com diversas encefalopatias. A partir desses pressupostos, objetivo dessa revisão é discutir a literatura científica sobre o uso dessas tecnologias na reabilitação da PC. O potencial para uso desta tecnologia na reabilitação de pacientes com PC é clara. Existe, contudo, carência de estudos randomizados para investigar se estes métodos são efetivamente capazes de complementar o processo de reabilitação física e neurocognitiva ou substituir os métodos de reabilitação tradicionais.

Palavras-chave: Reabilitação, realidade virtual, paralisia cerebral.

\section{Tecnología Computacional de la Realidad Virtual Aplicada a la Rehabilitación de la Parálisis Cerebral: Una Revisión de la Literatura}

\section{Resumen}

La parálisis cerebral (PC) es una encefalopatía no progresiva que provoca cambios en el tono muscular, postura y movimiento. La importancia de la intervención temprana en esta enfermedad es ampliamente reconocida. Por lo tanto, nuevas herramientas de tratamiento, como las tecnologías computacionales, han estado colaborando para la rehabilitación de estos pacientes. La computación, a través de juegos de realidad virtual $(\mathrm{RV})$, puede permitir la manipulación de las variaciones de intensidad del entrenamiento, y evaluar el progreso y la directa supervisión sobre las actividades del paciente. Algunos estudios han demostrado la eficacia de la utilización de estos sistemas para mejorar la gestión de las tareas de de las personas con diferentes encefalopatías. A partir de estas premisas, el objetivo del estudio es analizar la literatura científica sobre el uso de estas tecnologías en la rehabilitación de la PC. El potencial para uso de RV en la rehabilitación de pacientes con PC es clara. Sin embargo, hay una falta de ensayos aleatorios para investigar si estos métodos son capaces de complementar eficazmente la rehabilitación física y/o cognitiva o si pueden desplazar a los métodos más tradicionales de la rehabilitacion.

Palabras clave: Rehabilitación, realidad virtual, parálisis cerebral.

Cerebral palsy $(\mathrm{CP})$ results from non-progressive encephalopathy with localization in an immature brain (Fairhurst, 2011; Rotta, 2002). It is characterized by a disorder of tonus, movement and posture, which may lead to motor dysfunctions, cognitive disabilities and functional impairment (Aisen et al., 2011; Fairhurst, 2011; Jones, Morgan, Shelton, \& Thorogood, 2007; Rotta, 2002). CP is often accompanied by sensation, perception, communication and behavioral disturbances (Aisen et al., 2011; Anttila, AuttiRämö, Suoranta, Mäkelä, \& Malmivaara, 2008; Fairhurst, 2011; Gagliard et al., 2008).

The global aim for the health care of CP patients must include promotion of greater functional independence, acquisition of new skills, anticipation, prevention and treatment of complications for the patients as well as assistance and education to family members and caregivers in day-to-day care (Fairhurst, 2011; Jones, Morgan, \& Shelton, 2007). The condition is often permanent and needs multidisciplinary therapeutic follow-ups (Aisen et al., 2011; Fairhurst, 2011; Rotta, 2002), as well as psychological, educational and technological approaches to maximize the individual's potentiality, decrease morbidities and improve functional abilities and quality of life (Aisen et al., 2011; Jones, Morgan, Shelton, \& Thorogood, 2007).

The importance of early rehabilitation and intervention in CP is well accepted, and new tools have been developed to create contexts and situations capable of facilitating the interaction between patient and environment (Chen et al., 2007). In this way, games of virtual reality ambiance (VR) have been introduced as thera- 
peutic tools to circumvent possible difficulties in the rehabilitation set for CP (Chen et al., 2007; Golomb et al., 2010; Howcroft et al., 2012) as well as for other neurological disorders (Saposnik, Mamdani, et al., 2010).

VR has been defined as an immersive and three-dimensional experience simulating the real world (Deutsch, Borbely, Filler, Huhn, \& Guarrera-Bowlby, 2008). It is an example of computational technology capable of providing virtual contexts and objects allowing interaction between users with some proximity of reality. Over the last decade, this technology has been increasingly used as a tool for the treatment of motor and cognitive diseases (Chen et al., 2007; Grealy, Johnson, \& Rushton, 1999; Howcroft et al., 2012; Qiu et al., 2009).

Another computational technology being tested in rehabilitation sets is augmented reality (AR). Instead of "transporting" the user into the virtual environment, AR keeps the physical environment and implements the virtual scenario into the real space. It allows for an actual interaction with the virtual world (Correa, Assis, Nascimento, \& Lopes, 2008). The man-computer interaction allows users the opportunity to explore virtual environments, exercise and feel through multidimensional and multisensory channels, such as vision, hearing, touch and smell (Deutsch et al., 2008; Saposnik, Teasell, et al., 2010).

A patient's individual and virtual environment characteristics influence the spatial interaction. It is within this virtual environment that the individual develops a feeling of presence, which can assist in the learning process of presented tasks. This will allow functional development, improve motivation and reduce fatigue (Qiu et al., 2009). Therefore, computational technology has been used as an educational and therapeutic tool allowing flexibility and control over the treatment schedule (Chang, Chen, \& Huang, 2011; Martin-Moreno, Ruiz-Fernandez, Soriano-Paya, \& Berenguer-Miralles, 2008). In fact, programs of interactive games have long been tested in rehabilitation, allowing multiple players to take part in a single game scenario (Deutsch et al., 2008). Some of these games are reminiscent of the real world, such as tennis, golf and boxing, which require total or partial body movement (Deutsch et al., 2008; Howcroft et al., 2012).

Specifically for CP, VR therapy and any technology capable to motivate the patients through the rehabilitation techniques must offer security, feasibility of exercises, atentional focus on tasks and additional possibilities for social interaction (Chen et al., 2007; Deutsch et al., 2008).

The objective of this review is to discuss the use of VR technologies in rehabilitation processes of CP. We argue that the technology is widely available and, although important descriptions and studies have been published describing its use, it still needs more experimental data and randomized studies in this field. The therapeutic use of VR associated or not with other types of technology, such as AR or interactive gaming, is limited and needs more scientific attention.

\section{Method for Reference Searches Used in this Review}

Aiming to gather information, five database were consulted. The searches were directed toward English articles published from 2004 onward. Sources included Google Scholar, MEDLINE, the Cochrane Central Register of Controlled Trials, PsycNET and ScienceDirect. Electronic search terms included the combined "rehabilitation", "cerebral palsy" and "virtual reality".

Google Scholar is a wider search engine with no dedicated filters. It was used in the advanced search mode with restrictions to the date (2004-2014), excluding citations, patents and the restraining line command "filetype:pdf", which selects only articles available in the most common format for scientific publication. This strategy removes articles published in other formats including online publications from universities and academic and governmental institutions. To separate reviews from other articles, the keyword "reviews" was used, which includes the plural and singular items for that term. The same was used for clinical trials and controlled studies. 
The MEDLINE database was primarily accessed via PubMed search engine with more dedicated search filters. A 10 year restraining search filter was used. The Cochrane Library is a compilation of databases for healthcare and has a comprehensive collection of scientific medical literature. In Brazil, it works via BIREME interface (BVS - Biblioteca Virtual em Saúde). There are no term restrainers in this engine; therefore, it was used to limit "clinical trials" and "random-

Table 1

Surveying of Literature Related to the Search Terms "Rehabilitation", "Cerebral Palsy" and "Virtual Reality"

$\begin{array}{lcccc}\text { Source } & \text { Reviews } & \text { Clinical studies } & \text { Controlled trials } & \text { Total } \\ \text { Google Scholar* } & 685 & 107 & 106 & 833 \\ \text { MEDLARS } & 07 & 08 & 05 & 38 \\ \text { Cochrane** } & 07 & 09 & 03 & 44 \\ \text { PsychINFO } & 06 & 14 & 01 & 21 \\ \text { ScienceDirect } & 25 & 106 & \text { Not specified } & 136\end{array}$

Note. * Google Scholar does not specifically refrain searches for clinical studies. The results were obtained inserting commands for "review", "clinical trials" and "controlled trials". ** Cochrane is a library specific for systematic reviews.

\section{Virtual Reality Technology in Rehabilitation of Cerebral Palsy}

The difficulties of performing physical and cognitive tasks may undermine the perception of self-efficacy and competence of CP patients. Some researchers have addressed this situation, discussing neurological rehabilitation and virtual environments to deal with gross motor movements, coordination, range movements, skills and postural control (Chen et al., 2007; Reid, 2002; You et al., 2005).

As previously mentioned, VR is defined as an immersive and interactive experience with the properties to make the user feel absorbed or involved within the virtual environment, simulating the real world in real-time (Deutsch et al., 2008). VR systems combine hardware and software components to stimulate sensory information, creating a proximal to reality environment and capturing the patients' interest (Deutsch et al., 2008). The level of immersion in conjunction with the interactivity are key factors to establish ized controlled trials" as additional terms. The search on PsycNET was performed using the search engine from the American Psychological Association, which includes PsycINFO, PsycEXTRA and PsychARTICLES. ScienceDirect is a website that catalogues publications from Elsevier editors and includes about 2,200 journals in several languages, over 12 million articles and 26,000 books. All the searches were performed with the keywords and additional date filters imposed. The search results are shown in Table 1. 
to skills generalization (Wang \& Reid, 2011; Wilson, Foreman, \& Tlauka, 1996).

The employment of a virtual environment yields opportunities to conduct amusement activities and engage control over actions developing a sense of self-control and ownership (Reid, 2002). From a clinical point of view, VR systems offer control over systematic administration and incremental progression of duration, intensity and repetition of exercises and tasks not performed in real-world environments (Chen et al., 2007; Deutsch et al., 2008). Additional structures, such as instructions, suggestions, requests and feedback, are easily integrated into each step during the tasks (Chang et al., 2011; Qiu et al., 2009). This allows the necessary flexibility to individualize the intervention and integrate particular interests and preferences into the rehabilitation program, while varying the complexity of the tasks through the virtual environment. It is feasible to increase attentional stimuli, minimize distractions and exaggerate feedback to the performance (Chen et al., 2007; Qiu et al., 2009).

The possibility of using this equipment in commercial ways may promote use at home as an additional, pre-scheduled rehabilitation program as well as for family leisure (Berry et al., 2011; Bryanton et al., 2006; Golomb et al., 2010; Howcroft et al., 2012; Huber et al., 2010). Therefore, interactive VR use in video-game technology is being researched as a tool to improve the training for daily tasks even without repetitive, wellcontrolled practice (Berry et al., 2011; Huber et al., 2010). Patients' involvement in the task is a strong predictor of successful learning, thereby improving the response levels and sense of selfefficacy and self-control (Howcroft et al., 2012; Ma et al., 2011; Qiu et al., 2009; Shih, Shih, \& Chiang, 2010).

Another important consideration is the safety environment provided by VR activities, offering experience in perceived risky situations, which allows patients to execute difficult tasks in the real world (Miller \& Reid, 2003; Saposnik, Teasell, et al., 2010). Although there are possible situations at home that may raise parental concerns, such as jumping, ruining and hitting, the realism of the simulated environment allows for the development of self-trust. This provides a safe trial and prepares the patient and caretakers for dealing with the increased likelihood of these skills being transferred to daily life (Bryanton et al., 2006; Deutsch et al., 2008).

The intentional participation in rehabilitation is part of the treatment process and might be considered a key factor. The right game and environmental skills required to gain or exercise a pre-defined group of skills is fundamental to produce motivation in the competition of the virtual environment (Harris \& Reid, 2005). It is important to keep in mind that children with CP may be influenced by the conflict of goals of therapeutic activity and the difficulties to achieve them. The VR games might help to overcome this and be used as a base for motivation improvement (Berry et al., 2011).

The drive for active involvement and interest in the activities of the virtual environment seems to be fundamental to increase the motivation for learning (Howcroft et al., 2012; Reid, 2005). However, the environments that allow expression, creativity and control over the activity are generally considered to be more motivational. On the other hand, users whose game performances do not excel might feel frustrated or unmotivated. Therefore, the virtual therapeutic environments should be carefully planned and constructed in a gradually increasing and challenging way (Reid, 2004). It has been clear that VR should allow the user capabilities to become compatible with the requirements of the virtual world (Reid, 2004).

In addition, VR games may improve motor function activities by imitative learning promoting mirror neurons' circuitry activity in the primary motor cortex and cerebellum (Golomb et al., 2010; You et al., 2005). The feedback received during sensory training in VR is prominent for internalization of motor representation of targeted movement establishing or reinforcing neural networks and pathways (Golomb et al., 2010; You et al., 2005). In this direction, studies using functional magnetic resonance imaging showed that $\mathrm{CP}$ patients have measurable changes in neuroplasticity of sensory-motor primary cortex when training in VR (You et al., 
2005). Qiu and colleagues (2009) employed a system of robotics in conjunction with VR for treatment of $\mathrm{CP}$ hemiplegic individuals. The results suggest a feasibility of this integration, identifying improvement in performance, amplitude, coordination and movement efficiency (Qiu et al., 2009).

Likewise, Barton, Hawken, Foster, Holmes, and Butler (2013) used the system Computer Assisted Rehabilitation Environment 'CAREN' with a child with CP. Results showed, after six weeks of training, increased selective motor control of the pelvis and assisted movement from the trunk, improving the sitting posture (Barton et al., 2013).

VR may also act as a technique to intensify patients' practice providing three-dimensional spatial correlations between the degree of observed movement in the real world and in front of a computer screen. Such spatial representation allows visual feedback in performance knowledge and guidance, which are crucial for motor learning in individuals with $\mathrm{CP}$ (Chen et al., 2007).

All strategies capable of capturing the attention and motivating the person are considered fundamental for learning motor or cognitive skills. The application of a VR environment in the clinical setting emerges as an application to support exercises for different types of cerebral damage, expanding the therapeutic possibilities and exploring neuropsychology strategies in an integrated manner (Cardoso et al., 2006; Costa, Carvalho, \& Aragon, 2000).

Several studies have shown neuropsychological rehabilitation being conducted using a VR environment and improving executive function recovery: playful and challenging factors drive repetition in a progressive manner (Alves \& Carvalho, 2010; Cardoso et al., 2006). It has a possibility of increasing cognitive flexibility and decreasing the processing time of information, reducing fear of mistakes in virtual and real tasks (Alves \& Carvalho, 2010; Cardoso et al., 2006). Even individuals who play videogames for short periods showed performance improvements on a large number of visual perception and attention tasks (Alves \& Carvalho, 2010). Akhutina and colleagues (2003) found that general spatial abilities were improved in patients with $\mathrm{CP}$ after VR training, which improved spatial conceptualization with cognitive benefits.

In the case of individuals with $\mathrm{CP}$, depending on their condition, the need for a more mature level of motor function development may be needed (Qiu et al., 2009). For instance, the adverse effects of VR must be a concern. However, there have been minimal reports of visually induced nausea ('cybersickness'), visual fatigue, insufficient perception of depth and reduction of tactile feedback (Ma et al., 2011; Shelly, Wolffsohn, \& McBrien, 2005). Sensory processing, visual integration and proprioceptive information disturbances may also be an unwelcome problem, as well as vestibular system disturbs such as sweating, nausea, disorientation and headaches (Ma et al., 2011; Shelly et al., 2005).

There are systems designed for specific use in neurological rehabilitation and systems commercially developed that can be of use in rehabilitation. This equipment and these programs might become of intense utility for rehabilitation in neurological disorders, since the commercial prices will possibly make them more available (Deutsch et al., 2008; Jovanov et al., 2009). The cost, user-friendly set up and commercial accessibility might become key factors in the choice of equipment in rehabilitation (Deutsch et al., 2008; Shih, Shih, \& Shih, 2011). Equipment such as the Nintendo Wii ${ }^{\circledR}$ and Sensor Kinect ${ }^{\circledR}$ are technologies that are commercially available and have been used as tools in different clinical set.

\section{The Nintendo Wiiß in Rehabilitation}

One of these pieces of equipment that has been researched as a tool for neurological rehabilitation is the Nintendo Wii ${ }^{\circledR}$. As a wireless device that communicates via Bluetooth technology, it has singular features for the user to control position and movement. Its sensors explore three-dimensional space perception and it includes an avatar as a representation of the gamer on the screen (Deutsch et al., 2008; Shih et al., 2011). The user keeps a remote control in the hand and has to be capable of manipulating 
the object on the screen and in the real world (Deutsch et al., 2008). Therefore, it provides haptic feedback, producing a physical sensation of balance and movement via the interaction with objects in the virtual environment, thus increasing the feeling of immersion (Deutsch et al., 2008).

The modulation in the force, direction, speed and acceleration of the remote control in Nintendo Wii changes the amount of feedback provided to the user and reduces difficulties with uni-plantar motion detection (Deutsch et al., 2008). The equipment may include a platform balance device and multiple sensors for pressure allowing the users to play with balance adjustments, standing posture and gait (Deutsch et al., 2008; Shih, Shih, \& Chu, 2010).

The visual screen feedback facilitates the training by reinforcing the gradually more correct force or balance and improvement on the task. Saposnik, Mamdani, et al. (2010) stress that it is possible to reduce the speed of the game and make it useful also for cognitive impairment.

For all of these characteristics, the Nintendo Wii ${ }^{\circledR}$ has been considered a viable option for use in neurological and cognitive rehabilitation and, therefore, has been studied as a research tool (Gordon, Roopchand-Martin, \& Gregg, 2012; Howcroft et al., 2012). Abdalla, Prudent, Ribeiro, and Souza (2010) showed that the rehabilitation treatment for $\mathrm{CP}$ children, using Wii Fit ${ }^{\circledR}$ games with the Wii Balance Board $\AA$, was an efficient aid to traditional physiotherapy schedules and improved the discharge of weight and gravity center standing control.

Other studies have achieved similar results, showing improvement in standing control posture, and trunk and head control for CP patients undergoing therapy (Shih, Shih, \& Chiang, 2010; Shih, Shih, \& Chu, 2010; Shih et al., 2011). Deutsch and colleagues (2008) observed improvement in perceptual and visual processing in postural control and functional mobility of a CP patient (Deutsch et al., 2008).

Barcala, Colella, Araújo, Salgado, and Oliveira (2011) demonstrated that conventional physiotherapy associated with balance training acted as a feature for visual biofeedback, inter- action and motivation to perform tasks. The dynamic balance control and reduction of mediallateral plane oscillations and anterior-posterior plane of static balance were improved (Barcala et al., 2011).

In addition, the level of activity in the games are supplementary tools to improve daily physical activity and physical fitness (Howcroft et al., 2012; Hurkmans, VandenBerg-Emons, \& Stam, 2010). CP patients may achieve physical activity with mild to moderate intensity by practicing 30 minutes of Wii Sports ${ }^{\circledR}$ (Howcroft et al., 2012; Hurkmans et al., 2010). In a recent article, Howcroft and colleagues (2012) reported motor learning improvements in children with CP using different $\mathrm{Wii}{ }^{\circledR}$ game systems, which could be chosen depending on the therapeutic goals. Vibrotactile, visual, auditory and cognitive feedback may promote neuroplasticity changes. Therefore, interactive games, such as the Wii, may provide neuromuscular reeducation and an increase in complex and coordinated movements (Howcroft et al., 2012).

Berry and colleagues (2011) observed a wide variety of movements while the subjects played a Wii game, suggesting that these games could be used for rehabilitation beyond the clinical set and their home environment. In this case, considering the therapeutic goals, the right game could be recommended, targeting specific movement patterns. Consequently, if the goal for the game is to engage the children in repetitive practice of a specific movement, then it is necessary that the therapist instruct how the patient should perform the movement during the game to best achieve therapeutic goals (Berry et al., 2011).

Martin-Moreno and collaborators (2008) obtained significant results by using the Wii ${ }^{\circledR}$ remote control to direct the articular movements in at-home exercises. As the equipment provides a web link service, remote monitoring could be performed (Martin-Moreno et al., 2008). Therefore, the remote monitoring control allowed advising and correction of proper execution of each exercise, advising when the amplitude of movement or a repetition pattern was not equal to or was greater than initially established. In addi- 
tion, this assists the therapist to control whether the patient is performing the exercises proposed regularly, reaching greater treatment adherence (Martin-Moreno et al., 2008).

In view of the positive results in some studies, the implementation of the $\mathrm{Wii}{ }^{\circledR}$ in the rehabilitation schedule for patients with $\mathrm{CP}$ seems to be a point to be ameliorate in its application. For instance, the use of a remote control might limit the movements when hand control is required for this piece of equipment. Compared with other technologies available, such as movement sensors, which abolish the need for a physical connection, the remote might be of less use. However, all factors might be of use depending on the ability of the user and their therapists.

The advance and release of new commercial technologies might bring other possibilities, some of them very promising. For instance, the use in rehabilitation of the technology with movement detection like the Kinect ${ }^{\circledR}$ sensor.

\section{The Sensor Kinect® as Technology for Rehabilitation}

The Xbox360 Kinect ${ }^{\circledR}$ is a sort of game entertainment console commercially sold with an infra-red light sensor capable of following body movements without body markers or remotecontrols, making it naturally responsive (Chang et al., 2011; Clark et al., 2012). It allows the users to directly interact with the virtual world through body movement control. Therefore, the Xbox 360 Kinect ${ }^{\circledR}$ has been expanded to the rehabilitation context, promoting adherence to individualized training (Chang et al., 2011; Lange et al., 2011). The technology allows the users to create and control virtual, animated characters as avatars that can directly represent their movements and characteristics allowing the use of whole body and movements in such experience. This way, the focus is directed toward participating in the game and not their disabilities, forcing the training of motor skills and self-confidence (Lange et al., 2011).

Although current research employing this technology is still ongoing, few studies have shown encouraging results. Lange and colleagues (2011) observed improvement in transfer weight training rehabilitation, offering balance improvement for patients with neurological damage. An important factor for improvement in treatments using virtual technology seems to be linked to motivation (Chang et al., 2011). Chang and colleagues (2011) showed improvement in stand-alone functioning and self-determination of cognitively impaired patients. Hence, the console and sensor of the XBox Kinect ${ }^{\circledR}$ seem to be viable tools for cognitive rehabilitation, working the sense of self-criticism, determination and independence of patients with disabilities (Chang et al., 2011).

\section{AR as Technology for Rehabilitation}

Unlike VR, AR entwines physical and virtual environments where the user is located. Virtual and real objects are visible and specific, standardized real objects, or signals called "markers", are placed and virtual objects are associated to it (Tori \& Kirner, 2006). This technology involves three important aspects: (a) high quality of combined virtual and real environments; (b) high adjustment precision for object positioning and orientation in a real environment; (c) realtime interaction between virtual and real objects (Tori \& Kirner, 2006).

AR systems have been tested in rehabilitation with interesting results. The program Neuror proposed by Assis, Correa, Vaz, and Lopes (2008) is directed to physical rehabilitation of hemiplegic individuals and works as a mirror. It provides environments where the patient is able to self-observe in both virtual and real scenarios at the same time. A virtual arm in the same position replaces a hemiplegic patient's real arm (Assis et al., 2008). The perception of continuity provided by the virtual arm has effects on motor skills during the motor rehabilitation process using a virtually mirrored motor image (Assis, 2010).

Associate neurological rehabilitation for motor and cognitive deficits is a major challenge: both systems are usually set separately. Physical and motor disabilities are not necessar- 
ily separate from cognitive decline. The application ReabRA was created to stimulate cognitive functions in people with functional disabilities caused by illness or accidents (Nascimento, Carvalho, \& Rosa, 2008). The main objective is to assist in cognitive rehabilitation, aiming to stimulate perception, attention, memory, reasoning, problem-solving, language and executive functions for the treatment of different types of brain injury including CP (Nascimento et al., 2008). The system uses a webcam as the input device and a video monitor or a headset mounted display and a computer to process the images in high definition 3D models as the output device (Nascimento et al., 2008). The authors suggest running the process in a prepared room with markers placed in the positions in which the virtual objects must be to provide a more accurate sense of immersion. The patient is introduced to this room and visualizes the markers through monitors or a head mounted display and identifies the objects present in the image. After sometime, the patient is re-entered into the room and must identify the markers where the objects were placed (Nascimento et al., 2008).

The GenVirtual is another application that uses game driven conception to stimulate attention, concentration and memory linking colors and sounds to virtual objects designed in the real world (Correa, Assis, Nascimento, \& Lopes, 2007). The game provides motor learning, which occurs in accordance with the motor action schedule previously planned by the therapist conceiving the physical limitations (Correa et al., 2007; Correa et al., 2008). The use of GenVirtual with special needs patients has been tested as complementary therapy for motor rehabilitation. Results showed improvement in patients' motivation and satisfaction during rehabilitation treatment (Correa, 2011).

The use of AR environments can assist multidisciplinary teams to assess the motor learning capabilities of CP patients. Mawase, Bar-Haim, and Karniel (2011) observed deficits in planning and execution of hand movements in predictive upper limbs and the motor control of diplegic CP patients (Mawase et al., 2011). The use of available information and feedback control rather than anticipatory control by these patients may be more useful in daily manual activities (Mawase et al., 2011).

Although there is not a valuable amount of AR systems available for use in rehabilitation of neurological disabilities, these systems, in association with VR and traditional physical and neuro-cognitive rehabilitation planning, might promote new concepts for the treatment of such patients.

\section{Conclusions}

The aim of this review was to discuss the use of VR technologies in rehabilitation processes for CP and neurological disorders. The therapeutic use of VR associated or not with other types of technology (such as AR or interactive gaming) is limited and needs more scientific attention.

The use of VR in the rehabilitation of neurologically impaired patients now shows major scientific promise. Systems that are more sophisticated are appearing each day and the search for applications must be followed by serious clinical trials. VR technology has the capability of creating a motivating environment in which practice intensity, feedback and technical control may be manipulated to allow treatments that are more specific.

In physical and cognitive rehabilitation, VR and AR technologies might promote the necessary stimulation of important points in neuropsychomotor development in addition to motivation in a safe practice. These technologies may associate the treatment with motor development and cognitive impairment. It is possible to hypothesize that neuromotor and neurocognitive impairment as an effect of developmental disabilities (such as CP) are in conjunction to each other. As such, the treatment of both conditions might be more helpful if combined. They can play an important role in successful psychological and neuropsychological approaches. In short, the neuropsychological rehabilitation performed using virtual environments has been shown to be a valuable tool for cognitive training and recovery of executive functions. 
Although there are still very few clinical randomized studies, it is important to notice that the modality of rehabilitation therapy using the notion of virtual environments is wide. Studies aiming to observe adhesion, motivation, attention focus, feedback and repetition are present in any modality of planned neurological, motor and cognitive therapy. VR and interactive games exploit the same motivational condition, which is competition and target seeking. This can be transposed to an AR environment and conditions can even be combined. The main objective for the use and study of these technologies is to improve a gain in patients with neurological motor or cognitive disabling conditions.

There are still many other problems to be addressed in the study of human/technology interaction. Some of these problems have been studied in regular conditions. For instance, the problem of fatigue for exposition to three dimension images or VR sickness are well known issues that have been studied for commercial purposes: it also applies to a therapeutic set. However, perception in patients with neurological disorders might be an issue for the interaction. Limited body movements may also be important to some instances in the rehabilitation process.

These technologies, when fully developed and tested, will certainly play an important role in the future of cognitive and physical therapies for neurological disorders.

\section{References}

Abdalla, T. C. R., Prudent, C. O. M., Ribeiro, M. F. M., \& Souza, J. S. (2010). Analysis of the evolution of standing balance in children with cerebral palsy under virtual rehabilitation, aquatic therapy and physiotherapy traditional. Magazine Moves, 3(4), 181-186.

Aisen, M. L., Kerkovich, D., Mast, J., Mulroy, S., Wren, T. A., Kay, R. M., \& Rethlefsen, S. A. (2011). Cerebral Palsy: Clinical care and neurological rehabilitation. Lancet Neurological, 10(9), 844-852. doi:10.1016/S14744422(11)70176-4

Akhutina, T., Foreman, N., Krichevets, A., Matikka, L., Narhi, V., Pylaeva, N., \& Vahakuopus, J. (2003). Improving spatial functioning in chil- dren with cerebral palsy using computerized and traditional game tasks. Disability and Rehabilitation, 25(24), 1361-1371.

Alves, L., \& Carvalho, A. M. (2010). Videogame and its influence on attention test. Magazine Psychology Study, 15(3), 519-525.

Anttila, H., Autti-Rämö, I., Suoranta, J., Mäkelä, M., \& Malmivaara, A. (2008). Effectiveness of physical therapy interventions for children with cerebral palsy: A systematic review. BMC Pediatric, 8, 14. doi:10.1186/1471-2431-8-14

Assis, G. A. (2010). NeuroR: System to support the rehabilitation of the upper limbs of patients victims of strokes. São Paulo, SP: Polytechnic School, University of São Paulo.

Assis, G. A., Correa, A. D., Vaz, C. N., \& Lopes, R. D. (2008). NeuroR: System of augmented reality for physical rehabilitation of patients' victims of stroke. Retrieved November 18, 2012, from http://www.sbis.org.br/cbis11/arquivos/867.pdf

Barcala, L., Colella, F., Araújo, M. C., Salgado, A. S. I., \& Oliveira, C. S. (2011). Analysis of balance in hemiparetic patients after training program with Wii Fit. Physiotherapy in Movement, 24(2), 337-343. doi:http://dx.doi.org/10.1590/ S0103-51502011000200015

Barton, G. J., Hawken, M. B., Foster, R. J., Holmes, G., \& Butler, P. B. (2013). The effects of virtual reality game training on trunk to pelvis coupling in children with cerebral palsy. Journal of NeuroEngineering and Rehabilitation, 10, 15. doi:10.1186/1743-0003-10-15

Berry, T., Howcroft, J., Klejman, S., Fehlings, D., Wright, V., \& Biddiss, E. (2011). Variations in movement patterns during active video game play in children with cerebral palsy. Journal Bioengineering \& Biomedical Science, 1(1). doi:10.4172/2155-9538.S1-001.

Bryanton, C., Bosse, J., O’Brien, M., McLean, J., McCormick, A., \& Sveistrup, H. (2006). Feasibility, motivation and selective motor control: Virtual reality compared to conventional home exercise in children with cerebral palsy. Cyberpsychology \& Behavior, 9(2), 123-128.

Cardoso, L., Costa, R. M. M., Piovesana, A., Carvalho, J., Ferreira, H., Lopes, M., ...Brandão, G. (2006). Use of virtual environments in the rehabilitation of patients with brain injury by stroke and skull trauma. Paper presented at the X Brazilian Congress of Informatics in Health, Flori- 
anópolis, SC, Brazil. Retrieved May 31, 2013, from http://www.sbis.org.br/cbis/arquivos/786. pdf

Chang, Y. J., Chen, S. F., \& Huang, J. D. (2011). The Kinect-based system is physical rehabilitation: A pilot study for young adults with motor disabilities. Research and Developmental Disabilities, 32(6), 2566-2570. doi:10.1016/j. ridd.2011.07.002

Chen, Y. P., Kang, L. J., Chuang, T. Y., Doong, J. L., Lee, S. J., Tsai, M. W., ...Sung, W. H. (2007). Use of virtual reality to improve upper-extremity control in children with cerebral palsy: A single-subject design. Physical Therapy, 87(11), 1441-1457. doi:10.2522/ptj.20060062

Clark, R. A., Puah, Y. H., Fortin, K., Ritchie, C., Webster, K. E., Denehy, L., \& Bryant, A. L. (2012). Validity of the Microsoft Kinect for assessment of postural control. Gait and Posture, 36(3), 372-377. doi:10.1016/j.gaitpost.2012.03.033

Correa, A. G. D. (2011). Augmented reality for rehabilitation: A case study in music therapy. São Paulo, SP: Polytechnic School, University of São Paulo.

Correa, A. G. D., Assis, G. A., Nascimento, M., \& Lopes, R. D. (2007). GenVirtual: A music game in augmented reality to a id the physical rehabilitation and cognitive of individuals with special needs. Paper presented at the XVIII Brazilian Symposium of Informatics in Education, São Paulo, SP, Brazil.

Correa, A. G. D., Assis, G. A., Nascimento, M., \& Lopes, R. D. (2008). GenVirtual: A music game for rehabilitation of individuals with special needs. Brasilian Journal of Information Technology in Education, 16, 9-17. doi:10.1109/ ICVR.2007.4362120

Costa, R. M. E. M., Carvalho, L. A. V., \& Aragon, D. F. (2000). New computing Technologies in cognitive rehabilitation. Paper presented at the $3^{\text {rd }}$ Symposium of Informatics Argentine y Salud - Healthy, Tandil, Argentina.

Darter, B. J., \& Wilken, J. M. (2011). Gait training with virtual reality-based real-time feedback: Improving gait performance following transfemoral amputation. Physical Therapy, 91(9), 1385-1394. doi:10.2522/ptj.20100360

Deutsch, J. E., Borbely, M., Filler, J., Huhn, K., \& Guarrera-Bowlby, P. (2008). Use of a low-cost, commercially available gaming console (Wii) for rehabilitation of an adolescent with cerebral palsy. Physical Therapy, 88(10), 1196-1207.

Fairhurst, C. (2011). Cerebral palsy: The whys and hows. Archives of Disease Childhood Education and Practice Edition, 97, 122-131. doi:10.1136/ edpract-2011-300593

Gagliard, C., Maghini, C., Germiniasi, C., Stefanoni, G., Molteni, F., Burt, D. M., \& Turconi, A. C. (2008). The effect of frequency of cerebral palsy treatment: A matched-pair pilot study. Pediatric Neurological, 39(5), 335-340.

Golomb, M. R., McDonald, B. C., Warden, S. J., Yonkman, J., Saykin, A. J., Shirley, B., ...Burdea, G. C. (2010). In-home virtual reality videogame telerehabilitation in adolescents with hemiplegic cerebral palsy. Archives of Physical Medicine Rehabilitation, 91(1), 1-8. doi:10.1016/j. apmr.2009.08.153

Gordon, C., Roopchand-Martin, S., \& Gregg, A. (2012). Potential of the Nintendo $\mathrm{Wii}^{\mathrm{TM}}$ to the rehabilitation tool for children with cerebral palsy in a developing country: A pilot study. Physiotherapy, 98(3), 238-242. doi:10.1016/j. physio.2012.05.011

Grealy, M. A., Johnson, D. A., \& Rushton, S. K. (1999). Improving cognitive function after brain injury: The use of exercise and virtual reality. Archives of Physical Medicine Rehabilitation, 80(6), 661-667.

Harris, K., \& Reid, D. (2005). The influence of virtual reality play on children's motivation. Canadian Journal of Occupational Therapy, 72(1), 21-29.

Howcroft, J., Klejman, S., Fehlings, D., Wright, V., Zabjek, K., Andrysek, J., \& Biddiss, E. (2012). Active video game play in children with cerebral palsy: Potential for physical activity promotion and rehabilitation therapies. Archives of Physical Medicine Rehabilitation, 93(8), 1448-1456. doi:10.1016/j.apmr.2012.02.033

Huber, M., Rabin, B., Docan, C., Burdea, G. C., AbdelBaky, M., \& Golomb, M. R. (2010). Feasibility of modified remotely monitored in-home gaming technology for improving hand function in adolescents with cerebral palsy. IEEE Transactions on Information Technology in Biomedicine, 14(2), 526-534. doi:10.1109/ TITB.2009.2038995

Hurkmans, H. L., VandenBerg-Emons, R. J., \& Stam, H. J. (2010). Energy expenditure in adults with 
cerebral palsy playing Wii Sports. Archives of Physical Medicine Rehabilitation, 91(10), 15771581. doi:10.1016/j.apmr.2010.07.216

Jones, M. W., Morgan, E., Shelton, J. E., \& Thorogood, C. (2007). Cerebral palsy: Introduction and diagnosis (Part I). Journal of Pediatrics Health Care, 21(3), 146-152.

Jones, M. W., Morgan, E., \& Shelton, J. E. (2007). Primary care of the child with cerebral palsy: A review of systems (Part II). Journal of Pediatrics Health Care, 21(4), 226-237.

Jovanov, E., Hanish, N., Courson, V., Stinson, H., Webb, C., \& Denny, K. (2009). Avatar - The multi-sensory system for real time body position monitoring. Conference Proceedings: Annual International Conference of the IEEE Engineering in Medicine and Biology Society, 2462-2465.

Lange, B., Chang, C. Y., Short, E., Newman, B., Rizzo, A. S., \& Balls, M. (2011). Development and evolution of low cost game-based balance rehabilitation tool using the Microsoft Kinect sensor. Conference Proceedings: Annual International Conference of the IEEE Engineering in Medicine and Biology Society, 1831-1834. doi:10.1109/IEMBS.2011.6090521

Ma, H. I., Hwang, W. J., Fang, J. J., Kuo, J. K., Wang, C. Y., Leong, I. F., \& Wang, T. Y. (2011). Effects of virtual reality training on functional reaching movements in people with Parkinson's disease: A randomized controlled pilot trial. Clinical Rehabilitation, 25(10), 892-902. doi:10.1177/0269215511406757

Martin-Moreno, J., Ruiz- Fernandez, D., SorianoPaya, A., \& Berenguer-Miralles, V. (2008). Monitoring 3D movements for the rehabilitation of joints in physiotherapy. Conference Proceedings: Annual International Conference of the IEEE Engineering in Medicine and Biology Society, 4836-4839. doi:10.1109/ IEMBS.2008.4650296

Mawase, F., Bar-Haim, S., \& Karniel, A. (2011). Lack of predictive control in lifting series of virtual objects by individuals with diplegic cerebral palsy. IEEE Transactions on Neural Systems and Rehabilitation Engineering, 19(6), 686-695. doi:10.1109/TNSRE.2011.2170589

Miller, S., \& Reid, D. (2003). Doing play: Competency, control and expression. Cyberpsychology \& Behavior, 6(6), 623-633.
Nascimento, D. B., Carvalho, G. J., \& Rosa, R. M. (2008). ReabRA: Cognitive rehabilitation through an application of augmented reality. Paper presented at the $5^{\circ}$ Workshop of Virtual and Augmented Reality, João Pessoa, Paraíba, Brazil. Retrieved November 18, 2012, from http:// www2.fc.unesp.br/wrva/artigos/50466.pdf

Qiu, Q., Ramirez, D. A., Saleh, S., Fluet, G. G., Parikh, H. D., Kelly, D., \& Adamovich, S. V. (2009). The New Jersey Institute of Technology Robot-Assisted Virtual Rehabilitation (NJITRAVR) system for children with cerebral palsy: A feasibility study. Journal of Neuroengineering and Rehabilitation, 6, 40. doi:10.1186/17430003-6-40

Reid, D. (2004). The influence of virtual reality on playfulness in children with cerebral palsy: A pilot study. Occupational Therapy International, 11(3), 131-144.

Reid, D. (2005). Correlation of the pediatric volitional questionnaire with the test of playfulness in the virtual environment: The power of engagement. Early Child Development and Care, 175(2), 153-164.

Reid, D. T. (2002). Benefits of virtual play rehabilitation environment for children with cerebral palsy on perceptions of self-efficacy: A pilot study. Pediatric Rehabilitation, 5(3), 141-148.

Rotta, N. T. (2002). Cerebral Palsy: New therapeutic possibilities. Journal of Pediatric, 78(Suppl. 1), S48-S54.

Saposnik, G., Mamdani, M., Bayley, M., Thorpe, K. E., Hall, J., Cohen, L. G., \& Teasell, R. (2010). Effectiveness of virtual reality exercises in stroke rehabilitation (EVREST): Rationale, design and protocol of the pilot randomized clinical trial assessing the Wii gaming system. International Journal of Stoke, 5(1), 47-51. doi:10.1111/j.1747-4949.2009.00404.x

Saposnik, G., Teasell, R., Mamdani, M., Hall, J., McIlroy, W., Cheung, D., ...Bayley, M. (2010). Effectiveness of virtual reality using Wii gaming technology in stroke rehabilitation: A pilot randomized clinical trial and proof of principle. Stroke, 41(7), 1477-1484. doi:10.1161/ STROKEAHA.110.584979

Shelly, A. L., Wolffsohn, J. S., \& McBrien, N. A. (2005). The development of a symptom questionnaire for assessing virtual reality viewing using a head-mounted display. Optometry and Vision Science, 82(3), 168-176. 
Shih, C. H., Shih, C. T., \& Chiang, M. S. (2010). The new standing posture detector to enable people with multiple disabilities to control of an environmental stimulation by changing their standing posture through the Wii Balance Board. Research and Developmental Disabilities, 31(1), 281-286. doi:10.1016/j.ridd.2009.09.013

Shih, C. H., Shih, C. T., \& Chu, C. L. (2010). Assisting people with multiple disabilities actively correct abnormal standing posture with Nintendo Wii Balance Board through controlling environmental stimulation. Research and Developmental Disabilities, 31(4), 936-942. doi:10.1016/j. ridd.2010.03.004

Shih, C. H., Shih, C. J., \& Shih, C. T. (2011). Assisting people with multiple disabilities by actively keeping the head in an upright position with Nintendo Wii Remote Controller through the control of an environmental stimulation. Research and Developmental Disabilities, 32(5), 2005-2010. doi:10.1016/j.ridd.2011.04.008

Tori, R., \& Kirner, C. (2006). Fundamentals and technology of virtual and augmented reality. Paper presented at the VIII Symposium Virtual Reality, Belém, PA, Brazil.
Wang, M., \& Reid, D. (2011). Virtual reality in pediatric neurorehabilitation: Attention deficit, hyperactivity disorder, autism and cerebral palsy. Neuroepidemiology, 36(1), 2-18. doi:10.1159/000320847

Wilson, P. N., Foreman, N., \& Tlauka, M. (1996). Transfer of spatial information from a virtual to real environment in physically disabled children. Disability and Rehabilitation, 18(2), 633-637.

You, H. S., Jang, S. H., Kim, Y. H., Kwon, Y. H., Barrow, I., \& Hallett, M. (2005). Cortical reorganization induced by virtual reality therapy in a child with hemiparetic cerebral palsy. Developmental Medicine and Child Neurology, 47(9), 628-635.
Received: June, 04, 2013

$1^{\text {st }}$ revision: September, 30, 2013

Accepted: May, 05, 2014 